\title{
Stability of potato chips fried in vegetable oils with different degree of unsaturation. Effect of ascorbyl palmitate during storage
}

\author{
By L. Masson ${ }^{1}$, P. Robert ${ }^{1}$, M.C. Dobarganes ${ }^{2}$, C. Urra', N. Romero', J. Ortiz', E. Goicoechea ${ }^{3}$, \\ P. Pérez ${ }^{1}$, M. Salamé ${ }^{1}$, and R. Torres ${ }^{3}$ \\ ${ }^{1}$ Laboratorio de Química de Alimentos y Materias Grasas, Departamento de Ciencia de los \\ Alimentos y Tecnología Química, Facultad de Ciencias Químicas y Farmacéuticas, \\ Universidad de Chile, Casilla 233, Santiago 1, Chile. \\ E-mail:Imason@uchile.cl \\ ${ }^{2}$ Instituto de la Grasa, CSIC, Avda. Padre García Tejero 4. 41012 - Sevilla, España. \\ ${ }^{3}$ Facultad de Ciencias Agrarias, Universidad Austral de Chile.
}

\section{RESUMEN}

Estabilidad de patatas chips fritas en aceites vegetales de distinto grado de insaturación. Efecto del palmitato de ascorbilo durante el almacenamiento.

Se estudia la evolución de la oxidación a $60^{\circ} \mathrm{C}$ en patatas fritas con cuatro aceites vegetales de distinta relación ácidos grasos poliinsaturados/saturados (P/S): 5,4 para el aceite de girasol, 3,4 para el aceite de canola, 0,4 para una mezcla de oleína de palma $(80 \%)$ y aceite de canola $(20 \%)$ y 0,3 para la oleína de palma. Se estudia igualmente la influencia de la adición de palmitato de ascorbilo (AP) durante la conservación del producto frito con especial atención a su efecto sinergista sobre los antioxidantes naturales. La evolución de la oxidación en lotes de patatas, con y sin adición de AP, se determinó mediante las siguientes determinaciones analíticas: índice de peróxidos (PV), cuantificación de tocoferoles y tocotrienoles, y periodos de inducción (IT) en Rancimat. La degradación de los aceites durante el proceso de fritura fue muy baja puesto que los niveles de compuestos polares y de antioxidantes naturales fueron similares a los encontrados en aceites refinados. La evolución de los índices analíticos durante el almacenamiento mostraron la importancia primordial del grado de insaturación del aceite por encima de la cantidad y tipo de antioxidantes y de la adición de AP. Sin embargo, la adición de AP a las patatas fritas tuvo un claro efecto sinergista traducido en menores PV y mayores cantidades de antioxidantes naturales e IT para cualquier tiempo de almacenamiento.

PALABRAS-CLAVE: Aceites vegetales - Almacenamiento Estabilidad - Palmitato de ascorbilo - Patatas chips - Sinergismo.

\section{SUMMARY}

Stability of potato chip fried in vegetable oils with different degree of unsaturation. Effect of ascorbyl palmitate during storage.

Four vegetable oils with different polyunsaturated/saturated fatty acid ratio $(P / S): 5.2$ for sunflower oil, 3.4 for canola rapeseed oil, 0.4 for a blend of palm olein and canola rapeseed oil (80:20), and 0.3 for palm olein were assayed for stability of crisps fried in these oils during storage at $60^{\circ} \mathrm{C}$. The action of ascorbyl palmitate with special attention to its synergistic effect on the natural antioxidants was also tested by addition to the fried potatoes. The evolution of the oxidative stability was measured through peroxide value, quantitation of tocopherols and tocotrienols, and induction time (IT) by means of Rancimat.
Oil degradation during frying was very low as both polar compound percentages and natural antioxidant had similar levels to those present in refined oils. Evolution of analytical parameters during storage results indicated that oil unsaturation degree or $\mathrm{P} / \mathrm{S}$ had a much more importance on stability of the product than had the content and type of natural antioxidants and the addition of AP.

Nevertheless, addition of AP to the fried potatoes had a significant effect resulting in higher retention of natural antioxidants, higher IT and lower PV at any storage time.

KEY-WORDS: Ascorbyl palmitate - Potato chip - Stability - Storage - Synergism - Vegetable oils .

\section{INTRODUCTION}

Over the last forty years there has been a great increase in the consumption of frying fats and oils, following the development of a wide range of new fried and prefried foods. Main reason is that frying is a fast and convenient technique for production of foods with unique sensory properties of color, flavor, texture and palatability, highly appreciated by consumers (Erickson, 1996).

These positive changes are accompanied by some undesirable modifications of the frying medium. It is well known that, during the frying process, the oils or fats are exposed to high temperature in the presence of air and moisture. Under these conditions, they may undergo important changes due to hydrolytic, oxidative and thermal reactions resulting in the loss of quality of the frying oil and of the fried food (Dobarganes and Pérez Camino, 1991).

General modifications of the main fat constituents are known, although it is not easy to foresee the rate of fat degradation due to the high number of variables involved in the frying process (Arroyo et al., 1992; Cuesta et al., 1993, Jorge et al., 1996). Some of them are linked to the process itself, such as temperature, length of heating, continuous or discontinuous heating, turnover period, etc.; others to the food subjected to frying, or else to the fat or oil used e.g., unsaturation degree, initial quality, minor 
compounds and additives (Varela, 1985). Therefore, an important aim in frying is the selection of the adequate operating conditions to produce high quality foods and, consequently, to maintain a low degradation level in the frying oil.

In the case of fried foods that are stored, the deterioration of the oil starts during the frying process, but it continues during storage of the product as a consequence of lipid oxidation, which produces chemical and sensory changes reducing the consumer acceptance. (Che Man and Tan, 1999). In this respect, it is not only important the selection of the most adequate frying fat or oil among the different options in the market (Melton et al., 1993; Mounts et al., 1994; Warner et al., 1994; Tyagi and Vaishtha, 1996; Petukhov et al., 1999; Plessis and Meredith, 1999; Masson et al., 1999; Tompkins and Perkins, 2000; Masson et al., 2001) but also the maintenance of high levels of minor protective compounds, i.e., antioxidants and synergists, to delay degradation as longer as possible (MarquezRuiz et al., 1999).

The addition of minor compounds to increase stability of the frying fats and fried foods is a common practice in food industry. Silicone, antioxidants, either synthetic or natural, and synergistic compounds as citric acid or ascorbyl palmitate are good examples of additives whose utility to improve the performance of oils during frying and storage has been reported (Huang et al., 1995; Gordon and Kourimská, 1995a,b; Lampi et al., 1999; Wagner and Edmadfa., 1999; Kochhar, 2000).

In particular, the action of ascorbyl palmitate (AP) during heating and frying has been the subject of detailed investigations (Bruun-Jensen et al., 1994; Van Ruth et al., 1999; Mäkinen and Hopia, 2000). In some studies, addition of AP retarded formation of degradation compounds (Andrés, 1984; Gwo et al., 1985; Gordon and Kourimska, 1995a; Satyanarayana et al., 2000), and increase the stability of tocopherols (Gordon and Kourimska, 1995b). In other reports, no significant effect was found with respect to the oil without additive (Augustin et al., 1987; Ibrahim et al., 1991).

The protective effect of AP during oil storage has been also studied under different conditions. Thus, the effective oxygen quenching ability for the reduction of gamma irradiation-induced oxidation of oils (Lee et al.,1999 a,b) or for minimizing chlorophyll-sensitized photoxidation (Lee et al., 1997) has been demonstrated. Also, the efficacy of AP for increasing the chemical and sensory stability in combination with different antioxidants has been reported (McMullen et al., 1991; Hawrysh et al., 1992). Interestingly, a study on the antioxidative effect of tocopherols and AP emphasizes the need for different antioxidants to achieve optimum efficacy in different fats and oils as the AP effect greatly depended on fatty acid composition. (Timmermans and Adams, 1989). Also the reduction or inversion of the prooxidant activity of $\alpha$-tocopherol at high concentration by adding AP has been reported (Cillard and Cillard, 1986).

In a recent paper (Satyanarayana et al., 2000), the action of AP, alone and in combination with other antioxidants, on the quality of the frying peanut oil and shelf-life of potato chips was investigated. Addition of AP improved the quality of frying oil and doubled the shelf-life of the fried potatoes. However, when AP is added to the frying oil it is impossible to distinguish if the action during storage was a direct action or a indirect consequence of the better quality of the frying oils in the fried product. To establish its effect during storage of fried products, AP has to be added after frying.

The main objective of this study was to asses the synergistic effect of ascorbyl palmitate during the storage at $60^{\circ} \mathrm{C}$ of potato chips fried in four vegetable oils with different polyunsaturated/saturated fatty acid ratio.

\section{MATERIALS AND METHODS}

\subsection{Samples}

Refined sunflower oil (SFO) obtained from the local market, refined canola rapeseed oil (CRO) donated by Agromaule S.A., refined palm olein (PO) donated by Evercrisps S.A. and a blend of $80 \%$ palm olein and $20 \%$ canola rapeseed oil (BPOCRO) prepared in the laboratory to reduce the percentage of linolenic acid below $2 \%$, were the samples used in this study.

Raw potato chips were donated by Evercrisps S.A., a leader company in the Chilean market.

\subsection{Materials and reagents}

Ascorbyl palmitate (AP) was donated by ROCHE, S.A.. Silica gel 60 for column chromatography (particle size $0.063-0.100 \mathrm{~mm}$ ) and tocopherols and tocotrienols standard were purchased from Merck (Darmstadt, Germany). All other solvents and chemicals (of reagent grade or better quality) were obtained from local suppliers.

\subsection{Frying procedure}

$60 \mathrm{~kg}$ of raw potato chips were fried in each experience. A $36 \mathrm{~L}$-fryer with temperature regulation was used. The frying procedure for each vegetable oil tested was run in one day simulating the conditions of a continuous process. Lots of $900 \mathrm{~g}$ of raw potato chip were continuously fried for 3-4 min during $10 \mathrm{hr}$ and $1.5 \mathrm{~L} / \mathrm{h}$ of initial oil were added to replenish the fryer. Frying temperature was $180 \pm$ $10^{\circ} \mathrm{C}$. 


\subsection{Addition of ascorbyl palmitate}

After frying, a $2 \%$ solution of AP in ethanol was added to $\mathrm{NaCl}$ in order to obtain a concentration of $500 \mathrm{mg} / \mathrm{kg}$ in the fried potatoes, the maximum level permitted by the Chilean regulation (Reglamento Sanitario de los Alimentos, 1997).

The total amount of fried potato chips obtained for each vegetable oil $(20 \mathrm{~kg})$ was divided in two equal lots. One lot was put in a special designed rotating equipment and $1.3 \%$ salt, with the AP incorporated, was added to the product. The same procedure was used with the other lot but adding only the same percentage of salt. This batch corresponded to the control assay.

\subsection{Storage conditions and sampling}

Bags of 50 and $120 \mathrm{~g}$ of potato chips for each vegetable oil, both with and without addition of AP, were prepared and sealed with a manual machine in the laboratory using the common commercial metallized, polypropylene-laminated film. All the bags were stored in a camera with forced air in dark at $60^{\circ} \mathrm{C}$.

Potato chips fried in sunflower oil and canola rapeseed oil with and without $A P$ the bags were sampled at time zero and then every 48 hours for 16 days. For the experience using palm olein and the blend of palm olein with canola oil the bags were taken at time zero and then every 15 days for 120 days. Four bags were taken out every time for chemical analysis.

\subsection{Analytical methods}

Lipids from $50 \mathrm{~g}$ of ground potatoes were extracted with $150 \mathrm{~mL}$ of a mixture of petroleum ether:diethyl ether $(90: 10 \mathrm{v} / \mathrm{v})$ by stirring in a mechanical shaker. The solvent was separated by filtration on anhydrous sodium sulfate. The extraction procedure was repeated three times. The combined extracts were evaporated under vacuum in a rotary evaporator.

Fatty acid composition was determined by GLC in a HP 5890 with FID detector, capillary column fused silica BPX70, 50m, 0.25m i.d. Temperature was programmed from 160 to $230^{\circ} \mathrm{C}\left(2^{\circ} \mathrm{C} / \mathrm{min}\right)$ and hydrogen was used as carrier gas. Fatty acid methyl esters were prepared according to the standard method. (AENOR,1991).

Peroxide Value (PV) was determined by the standard method (AOCS, 1993).

Polar compounds (PC) was determined by adsorption chromatography following the standard method (IUPAC, 1987). Distribution of PC in the main groups of constituents, i.e. triglyceride polymers (TGP), triglyceride dimers (TGD), oxidized triglyceride monomers (oxTGM), diglycerides (DG) and fatty acids (FA), was determined by size exclusion chromatography (Dobarganes et al., 2000). The instrument was a Merck Hitachi with refractive index detector. Two 100 and $500 \AA$. Ultrastyragel columns $25 \mathrm{~cm} \times 0.77 \mathrm{~cm}$ inner diameter were connected in series, operating at $35^{\circ} \mathrm{C}$. Mobile phase was tetrahydrofuran $(1 \mathrm{ml} / \mathrm{min})$.

Tocopherols and tocotrienols were determined by HPLC with fluorescence detector (AOCS, 1993).

Induction time (IT) was evaluated by means of the Metrohm Rancimat (AOCS,1993).

\subsection{Data analysis}

Statgraphics Plus was used for the study of differences between treatments.

\section{RESULTS AND DISCUSSION}

Table I shows fatty acid composition of the four oils used in the study. As well as their polyunsaturated/saturated fatty acid ratio $(P / S)$ with values from 5.2 for SFO to 0.3 for PO. Selection of the frying oils was based on their use and availability. Thus, palm oil and palm olein are the most used in West Europe and South Africa as a good frying medium due to their high content of palmitic acid. SFO with the highest P/S ratio has the lowest resistance to thermoxidative alteration, but it is also used as a frying medium. CRO is cultivated in Chile in a small scale. It has a well balanced fatty acid composition being used as salad oil. It was considered interesting to study its behavior in frying process, although due to its content in linolenic acid, higher than $2 \%$, it is not permitted for industrial frying process by the Chilean regulation. Finally, the blend BPOCRO was prepared to test the performance of an oil with the maximum level of linolenic acid permitted by the Chilean regulation (Reglamento Sanitario de los Alimentos, 1997).

Table II summarizes the levels of polar compounds in fried potatoes before storage. Surprisingly, the oil degradation during frying was very low in all the samples in spite of the high number of frying operations carried out to prepare around $20 \mathrm{~kg}$ of fried potatoes. Results demonstrated that in good frying practices only small changes are expected as degradation was much lower than those expected in potato discontinuous frying (Masson et al., 1997) and similar to those found in industrial continuous frying of high turnover (Sebedio et al., 1996; Robert et al., 2001). After 10 hours of continuous frying operations, polar compounds were similar to those present in unused frying oils. SFO had the lowest polar compound content although a detailed analysis of their distribution showed that its level of polymeric compounds (TGD), the most characteristic group formed at high temperature (Dobarganes, 1998), was the highest. However, the high level of PC in the 
Table I

Fatty acid composition (\%) of the four oils used for frying potato chips

\begin{tabular}{c|c|c|c|c|c|c|c}
\hline & $\mathbf{C}_{16: 0}$ & $\mathbf{C}_{18: 0}$ & $\mathbf{C}_{18: 1}$ & $\mathbf{C}_{18: 2}$ & $\mathbf{C}_{18: 3}$ & Others & $\mathbf{P} / \mathbf{S}^{*}$ \\
\hline Sunflower oil & 6.4 & 3.7 & 29.0 & 58.0 & 0.4 & 2.5 & 5.2 \\
$\begin{array}{c}\text { Canola rapeseed oil } \\
\begin{array}{c}\mathbf{8 0 : 2 0} \text { blend palm } \\
\text { olein:canola oil }\end{array}\end{array}$ & 5.5 & 2.2 & 58.4 & 21.5 & 9.0 & 3.4 & 3.4 \\
$\quad$ Palm olein & 39.1 & 4.9 & 40.6 & 12.3 & 0.3 & 2.8 & 0.3 \\
\hline
\end{tabular}

* Polyunsaturated to saturated fatty acid ratio

Table II

Total polar compounds (PC) and their distribution in triglyceride dimers (TGD), oxidized triglyceride monomers (oxTGM), diglycerides (DG) and fatty acids (FA) in oils extracted from potatoes before storage

\begin{tabular}{c|c|c|c|c|c}
\hline & PC (\%) & TGD (\%) & OxTGM (\%) & DG (\%) & FA (\%) \\
\hline Sunflower oil & 4.0 & 1.1 & 1.5 & 1.2 & 0.2 \\
\hline Canola rapeseed oil & 9.8 & 0.5 & 5.3 & 2.8 & 1.2 \\
\hline $\begin{array}{c}\mathbf{8 0 : 2 0} \text { blend palm } \\
\text { Olein:canola oil }\end{array}$ & 8.9 & 0.6 & 1.4 & 6.6 & 0.3 \\
\hline Palm olein & 9.2 & 0.6 & 0.9 & 7.6 & 0.1 \\
\hline
\end{tabular}
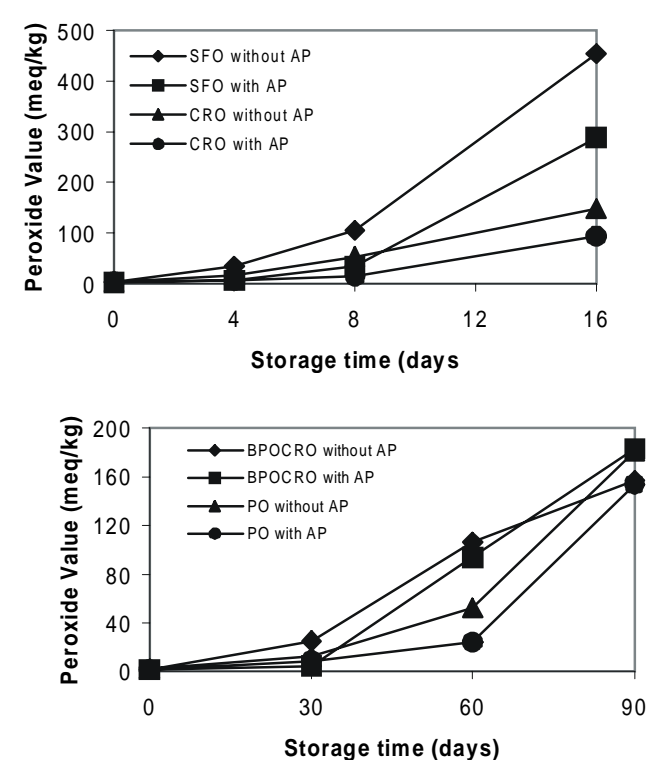

Figure 1

Evolution of peroxide value during the storage of potatoes fried in the different oils without and with ascorbyl palmitate added. stable PO and BPOCRO containing $80 \%$ of PO, can not be attributed to the frying process but to the high levels of diglycerides (DG) typical of palm oils (Goh and Timms, 1985).

Figure 1 shows the evolution of peroxide values (PV) of oils extracted from fried potatoes at increasing storage time. SFO and CRO, as expected, were less stable and reached high PV in 16 days while BPOCRO and PO had similar oxidation levels after three months. PV in SFO and CRO without AP showed a continuous increase from 4.3 to 453,5 and 4.8 to 148,5 respectively at 16 days of storage and, even if the addition of AP was not significant for decreasing their oxidation rate, $\mathrm{PV}$ values were lower in the samples with AP added at any storage time. It is also interesting to observe that, in spite of the content of linolenic acid in CRO, PV values were significantly lower $(p \leq 0.05)$ than those obtained for SFO both with and without AP added. These results suggest a better performance of CRO than that of regular SFO during storage of potato chips. The PV values for $\mathrm{PO}$ and BPOCRO without AP changed from 2.2 and $1.9 \mathrm{meq} / \mathrm{kg}$ after frying to 181.7 and $157.2 \mathrm{meq} / \mathrm{kg}$ at 90 days storage, respectively. 
Surprisingly no great differences were found when a $20 \%$ of canola oil was added to palm olein at the end of the storage period (90 days), even if, after two months, PV values for palm olein were much more lower than that found for the blend as can be observed in Figure 1.

Tables III to VI summarize the evolution of Induction times in Rancimat as well as the remaining amounts of natural antioxidants after different storage periods for the four oils extracted from potatoes. Induction times were determined at $100^{\circ} \mathrm{C}$ for SFO and $\mathrm{CRO}$ and at $130^{\circ} \mathrm{C}$ for BPOCRO and $P O$. From these results, the synergistic action of AP on the natural antioxidants resulting in the increase of the induction time was clearly established.

It is remarkable that the levels of tocochromanols in the initial samples were similar to those normally found in refined vegetable oils (Kamal-Eldin and Andersson, 1997) confirming the low degradation taking place during the frying process. In parallel, initial IT were also high and good stability against oxidation was expected.

Table III show the results for samples prepared in SFO. As can be observed the presence of AP contributed to increase the IT more than 60\% (from 12.7 to 20.3 hours) and consequently, the loss of $\alpha$-tocopherol was much more rapid when AP was absent. Even if significant differences were not found for PV, it was obvious that after 8 days the induction period had finished and after that tocopherols were rapidly exhausted, as previously reported (Martin Polvillo et al., 1996). In the case of potatoes with AP added, the end of the induction period seems to have occurred around 16 days.

A similar situation was found for CRO (Table IV). Although the increase of the induction time due to AP was only around $10 \%$ (from 24.5 to 27.8 ) the retention of tocopherols throughout the storage was much higher in the AP samples. As can be observed, at the end of the storage period only $2 \%$ of the initial tocopherols remained and IT was very low, denoting that the end of the induction period was being reached. For samples with AP, data at the end of the storage period (16 days) were of the same order than those found at 12 days for their counterpart samples without AP.

Tables $\mathrm{V}$ and $\mathrm{VI}$ shows the results for the more stable oils, which followed a similar profile to that found for SFO and CRO although storage time to reach the end of the induction period was much longer. The increase of IT due to AP addition was around $60 \%$ and $20 \%$ for BPOCRO and PO, respectively. The end of the induction periods for BPOCRO samples were between 30 and 45 days for samples without AP and between 45 and 60 days for samples with AP. As for PO samples, induction period was 0 between 60 and 75 days without AP added while the end of the induction period was close to 90 days due to the disappearance of natural antioxidants.

With respect to the relative loss of tocopherols, $\alpha$-tocopherol was the less stable as can be observed in all the samples and particularly in CRO and PO with high levels of $\gamma$-tocopherol remaining when

Table III

Evolution of induction times at $100^{\circ} \mathrm{C}(\mathrm{IT})$ and tocochromanols $(\mathrm{mg} / \mathrm{kg})$ in lipids extracted from potatoes chips fried in sunflower oil

\begin{tabular}{ccccccc}
\hline Sample & days & IT (hours) & $\alpha \mathrm{T}$ & $\beta \mathrm{T}$ & $\gamma \mathrm{T}$ & Total T \\
\hline & 0 & 12.7 & 671 & 22 & 8 & 701 \\
& 2 & 13.4 & 639 & 22 & 8 & 669 \\
Without & 4 & 4.6 & 562 & 22 & 8 & 592 \\
Ascorbyl & 6 & 3.3 & 249 & 19 & 7 & 275 \\
Palmitate & 8 & 0 & 115 & 5 & 0 & 120 \\
& 10 & 0 & 0 & 0 & 0 & 0 \\
& 12 & - & - & - & - & - \\
& 16 & 0 & 0 & 0 & 0 & 0 \\
With & & & & & & \\
Ascorbyl & 0 & 20.3 & 662 & 22 & 8 & 692 \\
Palmitate & 2 & - & - & - & - & \\
& 4 & 16.9 & 541 & 21 & 7 & 570 \\
& 6 & 11.4 & 513 & 19 & 8 & \\
& 10 & 7.4 & 497 & 15 & 2 & 514 \\
& 12 & - & 175 & 15 & 5 & 195 \\
& 16 & 1.0 & 20 & - & - & - \\
\hline
\end{tabular}

Abbreviation: T, tocopherol 
Table IV

Evolution of induction times at $100^{\circ} \mathrm{C}$ (IT) and tocochromanols $(\mathrm{mg} / \mathrm{kg})$ in lipids extracted from potatoes chips fried in canola rapeseed oil

\begin{tabular}{|c|c|c|c|c|c|c|c|}
\hline Sample & $\begin{array}{c}\text { Storage } \\
\text { time (days) }\end{array}$ & IT (hours) & $\alpha \mathrm{T}$ & $\beta \mathrm{T}$ & $\gamma \mathrm{T}$ & $\delta \mathrm{T}$ & Total T \\
\hline \multirow{8}{*}{$\begin{array}{l}\text { Without } \\
\text { Ascorbyl } \\
\text { Palmitate }\end{array}$} & 0 & 24.5 & 255 & 64 & 397 & 35 & 750 \\
\hline & 2 & - & - & - & - & - & - \\
\hline & 4 & 16.8 & 206 & 52 & 329 & 31 & 618 \\
\hline & 6 & - & - & - & - & - & - \\
\hline & 8 & 8.7 & 53 & 38 & 270 & 29 & 389 \\
\hline & 10 & - & - & - & - & - & - \\
\hline & 12 & 4.7 & 0 & 0 & 84 & 12 & 96 \\
\hline & 16 & 1.6 & 0 & 0 & 7 & 10 & 17 \\
\hline \multirow{8}{*}{$\begin{array}{c}\text { With } \\
\text { Ascorbyl } \\
\text { Palmitate }\end{array}$} & 0 & 27.8 & 214 & 49 & 332 & 27 & 623 \\
\hline & 2 & - & - & - & - & - & - \\
\hline & 4 & 22.3 & 213 & 49 & 316 & 28 & 606 \\
\hline & 6 & - & - & - & - & - & - \\
\hline & 8 & 23.4 & 149 & 38 & 257 & 24 & 468 \\
\hline & 10 & - & - & - & - & - & - \\
\hline & 12 & 13.2 & 90 & 41 & 274 & 28 & 433 \\
\hline & 16 & 4.5 & 0 & 0 & 122 & 19 & 142 \\
\hline
\end{tabular}

Abbreviation: T, tocopherol

Table V

Evolution of induction times at $130^{\circ} \mathrm{C}$ (IT) and tocochromanols $(\mathrm{mg} / \mathrm{kg})$ in lipids extracted from potatoes chips fried in 80:20 blend of palm olein and canola rapeseed oil

\begin{tabular}{|c|c|c|c|c|c|c|c|}
\hline Sample & $\begin{array}{c}\text { Storage } \\
\text { days }\end{array}$ & IT (hours) & $\alpha \mathrm{T}$ & $\alpha \mathrm{T} 3$ & $\gamma \mathrm{T}$ & $\gamma \mathrm{T} 3$ & $\begin{array}{c}\text { Total } \\
(T+T 3)\end{array}$ \\
\hline \multirow{7}{*}{$\begin{array}{l}\text { Without } \\
\text { Ascorbyl } \\
\text { Palmitate }\end{array}$} & 0 & 9.0 & 220 & 63 & 64 & 72 & 419 \\
\hline & 15 & 6.5 & - & - & - & - & - \\
\hline & 30 & 3.4 & 105 & 26 & 45 & 54 & 230 \\
\hline & 45 & 0 & 0 & 0 & 2 & 2 & 4 \\
\hline & 60 & 0 & 0 & 0 & 0 & 0 & 0 \\
\hline & 75 & - & - & - & - & - & - \\
\hline & 90 & 0 & 0 & 0 & 0 & 0 & 0 \\
\hline \multirow{7}{*}{$\begin{array}{l}\text { With } \\
\text { Ascorbyl } \\
\text { Palmitate }\end{array}$} & 0 & 14.5 & 227 & 65 & 66 & 74 & 432 \\
\hline & 15 & 10.1 & - & - & - & - & - \\
\hline & 30 & 5.7 & 188 & 47 & 54 & 60 & 348 \\
\hline & 45 & 5.3 & 93 & 18 & 38 & 56 & 205 \\
\hline & 60 & 0 & 0 & 0 & 0 & 0 & 0 \\
\hline & 75 & - & - & - & - & - & - \\
\hline & 90 & 0 & 0 & 0 & 0 & 0 & 0 \\
\hline
\end{tabular}

Abbreviations: T, tocopherol; T3, tocotrienol.

$\alpha$-tocopherol was exhausted, confirming the previous results (Yoshida et al., 1991, 1993). As for tocotrienols, evolution in PO samples would indicate a similar stability than their relative tocopherols, i.e., $\alpha$-tocopherol $=\alpha$-tocotrienol $<\gamma$-tocopherol $=$ $\gamma$-tocotrienol.

Finally excellent linear correlations coefficients, ranging from 0.836 and 0.988 , were found between 
Table VI

Evolution of induction times at $130^{\circ} \mathrm{C}$ (IT) and tocochromanols $(\mathrm{mg} / \mathrm{kg})$ in lipids extracted from potatoes chips fried in palm olein

\begin{tabular}{|c|c|c|c|c|c|c|c|}
\hline Sample & $\begin{array}{c}\text { Storage } \\
\text { days }\end{array}$ & IT (hours) & $\alpha \mathbf{T}$ & $\alpha \mathrm{T3}$ & $\gamma T 3$ & $\delta \mathrm{T} 3$ & $\begin{array}{c}\text { Total } \\
(T+T 3)\end{array}$ \\
\hline \multirow{7}{*}{$\begin{array}{l}\text { Without } \\
\text { Ascorbyl } \\
\text { Palmitate }\end{array}$} & 0 & 13.7 & 148 & 179 & 204 & 39 & 570 \\
\hline & 15 & - & - & - & - & - & - \\
\hline & 30 & 10.2 & 122 & 147 & 199 & 39 & 507 \\
\hline & 45 & - & - & - & - & - & - \\
\hline & 60 & 3.6 & 15 & 17 & 81 & 22 & 135 \\
\hline & 75 & 0 & 0 & 0 & 6 & 13 & 19 \\
\hline & 90 & 0 & 0 & 0 & 0 & 0 & 0 \\
\hline \multirow{7}{*}{$\begin{array}{c}\text { With } \\
\text { Ascorbyl } \\
\text { Palmitate }\end{array}$} & 0 & 16.5 & 147 & 170 & 205 & 35 & 557 \\
\hline & 15 & - & - & - & - & - & - \\
\hline & 30 & 13.9 & 131 & 150 & 205 & 36 & 522 \\
\hline & 45 & - & - & - & - & - & - \\
\hline & 60 & 6.2 & 106 & 123 & 186 & 34 & 449 \\
\hline & 75 & 6.0 & 0 & 0 & 61 & 18 & 79 \\
\hline & 90 & 3.0 & 0 & 0 & 0 & 0 & 0 \\
\hline
\end{tabular}

Abbreviations: T, tocopherol; T3, tocotrienol.

IT and total tocochromanols for all the oils both without and with AP. For each oil, the values of the slopes indicated a more rapid disappearance of tocochromanols when AP was not added to the fried product and in any case the intercept was significantly different from 0 , consistent with total exhaustion of natural antioxidants for $\mathrm{IT}=0$.

\section{CONCLUSIONS}

1. Under good practice conditions simulating continuous frying, degradation was extremely low and levels of both polar compounds and tocopherols in oils extracted from fried potatoes were similar to those found in unused frying oils independently of the degree of unsaturation of the oil used for frying.

2. Stability during storage followed the order expected considering fatty acid composition and P/S ratio: $\mathrm{PO}+\mathrm{AP}>\mathrm{PO}>\mathrm{BPOCRO}+\mathrm{AP}>\mathrm{BPOCRO}>>$ $\mathrm{CRO}+\mathrm{AP}>\mathrm{CRO}>\mathrm{SFO}+\mathrm{AP}>\mathrm{SFO}$. Therefore, under the conditions used, differences in stability were primarily due to the influence of oil unsaturation as the less stable oils, SFO and CRO, had initial antioxidant levels higher than those present in $\mathrm{PO}$ and BPOCRO.

3. Addition of AP to the fried product significantly contributed to increase stability during storage by increasing the initial Rancimat IT and decreasing the loss rate of tocopherols and tocotrienols.

\section{ACKNOWLEDGMENTS}

This work has been supported by FONDECYT PROJECT №1981056. Our special acknowledgment to the private industries contributing with raw materials to this study.

\section{BIBLIOGRAPHY}

AENOR. (1991). Asociación española de normalización. norma UNE 55037-73. Catálogo de normas UNE, Madrid.

Andrés, C. (1984). Ascorbic acid ester significantly increases life of frying oil. Food-Processing, 45, (8) 22-23.

AOCS. (1993) Official Methods and recommended Practices of the American Oil Chemist's Society, Champaign Illinois.

Arroyo, R., Cuesta, C., Garrido-Polonio, C., López-Varela, S. and Sánchez-Muniz, F.J. (1992). High-performance size-exclusion chromatographic studies on polar components formed in sunflower oil used for frying. J. Am. Oil Chem. Soc. 69, 557-563.

Augustin, M.A., Chua, C.J. and Heng, L.K. (1987). Effects of silicone and ascorbyl palmitate on the quality of palm olein used for frying of prawn crackers. J. Sci. Food Agr. 40 , 87-93.

Bruun-Jensen, L., Skovgaard, Ib M., Skibsted, L.H. and Bertelsen, G. (1994). Antioxidant synergism between tocopherols and ascorbyl palmitate in cooked, minced turkey. Z. Lebesm. Unters. Forsch. 199, 210-213.

Che Man, Y.B. and Tan, C.P. (1999). Effects of natural and synthetic antioxidants on changes in refined, bleached, and deodorized palm olein during deep-fat frying of potato chips. J. Am. Oil Chem. Soc. 76, 311-339. 
Cillard, J. and Cillard, P. (1986). Inhibitors of the prooxidant activity of alpha-tocopherol. J. Am. Oil Chem. Soc. 63, 1165-1169.

Cuesta, C., Sánchez-Muniz, F.J. Garrido-polonio, C., López-Varela, S. and Arroyo, R. (1993). Thermoxidative and hydrolytic changes in sunflower oil used in frying with a fast turnover of fresh oil. J. Am. Oil Chem.Soc. 70, 1069-1073.

Dobarganes, M.C. and Pérez-Camino, M.C. (1991). Frying process: Selection of fats and quality control.Proceedings of the international meeting of fats and oils.- Ed. D. Barrera, and L.A. Guaraldo. pp 58-67.

Dobarganes, M.C. (1998). Formation and analysis of high molecular-weight compounds in frying fats and oil. OCL, 5, 41-47.

Dobarganes, M.C., Velasco, J. and Dieffenbacher, A. (2000). The determination of polar compounds, polymerised triacylglycerols, oxidised triacylglycerols and diacylglycerols in fats and oils. Pure Appl. Chem. 72, 1563-1575.

Erickson, D.R., (1996). Current and future frying issues en Deep Frying. Chemistry, Nutrition and Practical Applications, ed. Perkins EG. and Erickson MD. American Oil Chemists' Society, Champaign, Illinois, pp 343-345.

Goh, E.M. and Timms, R.E. (1985). Determination of mono and diglycerides in palm oil, oleic and stearin. J. Am. Oil Chem. Soc. 62, 730-734.

Gordon, M.H. and Kourimská, L. (1995a). The effects of antioxidants on changes in oils during heating and deep frying. J. Sci. Food Agric. 68, 347-353.

Gordon, MH. and Kourimská, L. (1995b). Effect of antioxidants on losses of tocopherols during deep-fat frying. Food Chemistry, 52, 175-177.

Gwo, Y.Y., Flick, G.J., Jr; Dupuy, H.P. Ory, R.L. and Baran, W.L. (1985). Effect of ascorbyl palmitate on the quality of frying fats for deep frying operations.- J. Am. Oil Chem.Soc. 62, 1666-1671

Hawrysh, Z.J., Erin, M.K. and Lin, Y.C. and Hardin, R.T. (1992). Propyl gallate and ascorbyl palmitate affect stability of canola oils in accelerated storage. J. Food Sci. 57, 1234-1238.

Huang, S.W., Frankel, E.N. and Germain, J.B. (1995). Effects of individuals tocopherols and tocopherol mixtures on the oxidative stability of corn oil triglycerides. J. Agric. Food Chem. 43, 234-235.

Ibrahim, K., Augustin, M.A. and Ong, A.S.H. (1991). Effects of ascorbyl palmitate and silicone on frying performance of palm olein. Pertanika. 14, 53-57.

IUPAC. (1987). Standard methods for the analysis oils and fats and derivatives. $7^{\text {th }}$ edition, Pergamon Press, Oxford, England.

Jorge, N., Márquez-Ruiz, G., Martín-Polvillo, M., Ruiz-Méndez, M.V. and Dobarganes M.C. (1996). Influence of dimethylpolysiloxane addition to edible oils: dependence on the main variables of the frying process. Grasas y Aceites, 47, 14-19.

Kamal-Eldin, A. and Andersson, R. (1997). A multivariate study of the correlation between tocopherol content and fatty acid composition in vegetable oils. J. Am. Oil Chem. Soc. 74, 375-380.

Kochkar, S.P. (2000). Stabilization of frying oils with antioxidative components. Eur. J. Lipid Sci. Technol. 102, 552-559.

Lampi, A.M., Kataja, L., Kamal-Eldin, A. and Piironen, V. (1999). Antioxidant activities of alpha and gamma tocopherols in the oxidation of rapeseed oil triacylglycerols. J. Am. Oil Chemists' Soc. 76, 749-755.
Lee, K.H., Jung, M.Y. and Kim, S.Y. (1997). Quenching mechanism and kinetics of ascorbyl palmitate for the reduction of the photosensitized oxidation of oils. J. Am. Oil Chem. Soc. 74, 1053-1057.

Lee, K.H., Yook, H.S., Lee, J.W., Kim, S.K., Kim, M.J. and Byun, M.W. (1999). Effects of antioxidants on oxidation of tallow by gamma irradiation. Korean J. Food Sci. Technol. 31, 7-12,

Lee, K.H., Yook, H.S., Lee, K.W., Park, W.J., Kim, K.S. and Byun, M.W. (1999). Quenching mechanism and kinetics of ascorbyl palmitate for the reduction of the gamma irradiation-induced oxidation of oils. J. Am. Oil Chem. Soc. 76, 921-925.

Mäkinen, E.M. and Hopia, A.I. (2000). Effects of alpha-tocopherol and ascorbyl palmitate on the isomerization and decomposition of methyl linoleate hydroperoxides. Lipids, 35, 1215-1223.

Márquez Ruiz, G., Martín Polvillo, M., Jorge, N., Ruiz Méndez, M.V. and Dobarganes, M.C. (1999). Influence of used frying oil quality and natural tocopherol content on oxidative stability of fried potatoes. J. Am. Oil Chem. Soc. 76, 421-425.

Martín-Polvillo, M., Márquez-Ruiz, G., Jorge, N., Ruiz-Méndez, M.V. and Dobarganes, M.C. (1996). Evolution of oxidation during storage of crisps and french fries prepared with sunflower oil and high oleic sunflower oil. Grasas y Aceites, 47, 54-58.

Masson, L., Robert, P., Izurieta, M., Romero, N. and Ortiz, J. (1999). Fat deterioration in deep fat frying of "french fries" potatoes at restaurant and food shop sector. Grasas y Aceites, 50,460-468.

Masson, L., Robert, P., Romero, N., Izurieta M., Ortiz, J. y Dobarganes, M.C. (1997). Comportamiento de aceites poliinsaturados en la preparación de patatas fritas para consumo inmediato: formación de nuevos compuestos y comparación de métodos analíticos. Grasas y Aceites, 48, (5), 273-281.

Masson, L., Urra, C., Izaurieta M., Ortiz, J., Robert, P., Romero, N. y Witting, E. (2001). Estabilidad de papas crisps sometidas a diferentes condiciones de almacenamiento. Grasas y Aceites, 52, (3-4) 175-183.

McMullen, L.M., Hawrysh, Z.J., Lin, C. and Tokarskan, B. (1991). Ascorbyl palmitate efficacy in enhancing the accelerated storage stability of canola oil. J. Food Sci. $56,1651-1654$.

Melton, S.L., Trigiano, M.K., Penfield, M.P. and Yang, R. (1993). Potato chips fried in canola and/or cottonseed oil maintain high quality. J. Food Sci. 58, 1079-1083.

Mounts, T.L., Warner, K., List, G.R., Neff, W.E. and Wilson, R.F. (1994). Low-linolenic acid soybean oils-alternatives to frying oils. J. Am. Oil Chemists'Soc. 71, 495-499.

Petukhov, I., Malcolmson, R.J., Przybylski, R. and Amstrong, L. (1999). Frying performance of genetically modified canola oils. J. Am. Oil Chem. Soc. 76, 627-632.

Plessis, L.M.du. and Meredith, A.J. (1999). Palm oleic quality parameter changes during industrial production of potato chips. J. Am. Oil Chem. Soc. 76, 731-738.

Reglamento Sanitario de los Alimentos (1997). Ministerio de Salud. Diario Oficial de la República de Chile, Mayo 13 de 1997.

Robert, P., Masson, L., Romero, N., Dobarganes, M.C., Izaurieta, M., Ortiz, J. and Wittig, E. (2001). Fritura industrial de patatas crisps. Influencia del grado de insaturación de la grasa de fritura durante el almacenamiento. Grasas y Aceites, 52, (6) 389-396.

Satyanarayana, A., Giridhar, N., Joshi, G..J. and Rao, D.G. (2000). Ascorbyl palmitate as an antioxidant for deep 
fat frying of potato chips in peanut oil. J. Food-Lipids, 7, 1-10.

Sébédio, J.L., Dobarganes, M.C., Márquez, G., Wester, I., Christie, W.W., Dobson, G., Zwobada, F., Chardigny, J.M., Mairot, Th. and Lahtinen, R. (1996). Industrial production of crisps and prefied french fries using sunflower oils. Grasas y Aceites, 47, 5-13.

Timmermann, F. and Adams, W.F. (1989). Antioxidative effect of tocopherols and ascorbyl palmitate. Eur. Food Drink-Rev. 48, 51-52.

Tompkins, C. and Perkins, E.G. (2000). Frying performance of low-linolenic acid soybean oil. J. Am. Oil Chem. Soc. 77, 223-229.

Tyagi, V.K. and Vaishtha, A.K. (1996). Changes in the characteristics and composition of oils during deep-fat frying. J. Am. Oil Chem. Soc. 73, 499-506.

Van Ruth, S.M., Roozen, J.P., Posthumus, M.A. and Jansen, F.J.H.M. (1999). Influence of ascorbic acid and ascorbyl palmitate on the aroma composition of an oxidized vegetable oil and its emulsion. J. Am. Oil Chem. Soc. 76, 1375-1381.

Varela, G. Current facts about the frying of Foods in: Frying of Foods, chap. 1, 9-25. Ed: Varela, G., Bender, A.E., Morton, I.D., VCH Chichester, England (1985).
Wagner, K.H. and Elmadfa, I. (1999). Nutrient antioxidants and stability of frying oils: Tocochromanols, Beta-Carotene, Phylloquinone, Ubiquinone 50." In: Frying of Foods.- Chapter 7.- 163-182. Edited by D. Boskou and I. Elmadfa. Technomic Pubhishing Co. Inc. Lancaster U.S.A.

Warner, K., Orr, P., Parrot, L. and Glynn, M. (1994). Effects of frying oil composition on potato chip stability. J. Am. Oil. Chem. Soc. 71, 1117-1121.

Yoshida, H., Hirooka, N. and Kajimoto, G. (1991). Microwave heating effects on relative stabilities of tocopherols in oils. J. Am. Oil Chem. Soc. 56, 1042-1046.

Yoshida, H., Kajimoto, G. and Emura, S. (1993). Antioxidant effects of d-tocopherols at different concentrations in oils during microwave heating. J. Am. Oil Chem. Soc. 70, 989-995. 